\title{
Utilizing Bots for Sustainable News Business: Understanding Users' Perspectives of News Bots in the Age of Social Media
}

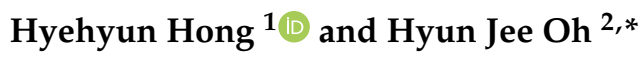 \\ 1 Department of Advertising and Public Relations, Chung-Ang University, Seoul 06974, Korea; \\ hhong@cau.ac.kr \\ 2 Department of Communication Studies, Hong Kong Baptist University, Kowloon Tong, Kowloon, \\ Hong Kong SAR, China \\ * Correspondence: hyunjoh@hkbu.edu.hk
}

Received: 15 July 2020; Accepted: 10 August 2020; Published: 12 August 2020

\begin{abstract}
The move of news audiences to social media has presented a major challenge for news organizations. How to adapt and adjust to this social media environment is an important issue for sustainable news business. News bots are one of the key technologies offered in the current media environment and are widely applied in news production, dissemination, and interaction with audiences. While benefits and concerns coexist about the application of bots in news organizations, the current study aimed to examine how social media users perceive news bots, the factors that affect their acceptance of bots in news organizations, and how this is related to their evaluation of social media news in general. An analysis of the US national survey dataset showed that self-efficacy (confidence in identifying content from a bot) was a successful predictor of news bot acceptance, which in turn resulted in a positive evaluation of social media news in general. In addition, an individual's perceived prevalence of social media news from bots had an indirect effect on acceptance by increasing self-efficacy. The results are discussed with the aim of providing a better understanding of news audiences in the social media environment, and practical implications for the sustainable news business are suggested.
\end{abstract}

Keywords: news bots; self-efficacy; prevalence of bot news; social media bots; social media news; sustainable news business

\section{Introduction}

The development of social media, like other technologies, has influenced news business in both how news is produced and consumed [1]. Social media have become a major source of news and information [2-4], and about two-thirds of Americans access news from social media (62\% in 2016, $67 \%$ in 2017, and $68 \%$ in 2018) [3]. People who use news on social media often show a different consumption pattern compared to those who use news through traditional news outlets (e.g., newspaper and television). For example, they pay less time and attention to news reports, and news reading is fragmented and re-contextualized within a wide range of contents on social media [5]. The consumption of news on social media tends to be brief and highly selective [6-8]. These changes in the social media environment have produced significant challenges for news organizations to overcome [2]. In particular, news organizations are now experiencing a loss of authority in deciding news values, creating a hierarchy of news reports accordingly, and delivering them to audiences [5]. Thus, understanding the social media environment and the audiences who use social media for news is an important issue for sustainable news business. 
Under such circumstances, news bots offer an opportunity for many news organizations to adapt and adjust to the social media environment. Bots can complement journalists by handling routine tasks and by assisting diverse journalistic processes such as fact-checking so that journalists can invest more time on investigative reporting $[9,10]$. In addition, utilizing bots in news production and dissemination enhances performance agility without any additional marginal costs [11]. Thus, Edwards et al. [12] advised organizations with limited resources to use social bots for effective information dissemination, as they showed bot accounts were perceived to be as credible as human accounts for news sources. Although there are positive sides to utilizing bots in news business, some scholars are concerned that the algorithmic process of news production and dissemination can potentially pollute the transparency of news production because the automated decision-making processes based on computational algorithms are not currently monitored, corrected, or criticized in the journalistic norm of transparency $[13,14]$.

The mixed views regarding the application of news bots have also been examined from the audience perspective. A recent survey of the US population by the Pew Research Center [15] showed that responses were closely tied between accepting and not accepting the use of bots by news organizations (referred to as news bots hereafter). Given that a significant portion of news on social media currently originates from bots [16], how news audiences think about this new technology is key to understanding news audiences in the social media environment. Nevertheless, little research has been documented on how people perceive news bots from the perspective of news audiences or users $[10,17,18]$.

This study aimed to fill the current void by investigating what makes people accept bots being adopted by news organizations. Particularly, we focused on how confident individuals are in identifying content from a bot (i.e., self-efficacy) and how prevalent they perceive it to be on social media (i.e., perceived prevalence) as potential predictors of the acceptance. In addition, we extended the study by exploring how the acceptance of news bots is related to their evaluation of social media news in general. By doing so, the current study is expected to provide news organizations with important insights into news audiences in the current social media environment.

\subsection{News Bots: The Use of Bots in News Organizations}

Lokot and Diakopoulos [10] defined news bots as "automated accounts that participate in news and information dissemination on social networking platforms" by automating journalistic tasks including news reporting and writing, curation, and data analysis (p. 683). By identifying and investigating 60 news bots on Twitter, Lokot and Diakopoulos [10] argued that news bots provide a significant opportunity for news organizations and journalists. In addition to simple tasks, such as rebroadcasting or replication, bridging between traditional news outlets and social media, and curation or aggregation of content from multiple sources, news bots can be useful in facilitating citizen journalism and creating customized content for micro-audiences based on geography and interests. Additionally, taking advantage of algorithm-based functions, Lokot and Diakopoulos [10] suggested that bots should be used for diverse journalistic processes, such as fact-checking and information verification, question-asking, and producing interactive news. As such, the use of news bots is considered to be an advanced technology that can complement journalists by handling routine tasks so that journalists can invest more time in investigative reporting [9-11]. Similarly, Edwards et al. [12] discussed the potency of news bots as a useful and ethical information channel. Based on the results of an experiment using a health promotion message to prevent sexually-transmitted diseases from the Centers for Disease Control and Prevention, Edwards et al. [12] showed that communication with bot accounts in Twitter was perceived as credible, attractive, competent, and interactional, as much as that with human accounts. Thus, they argued that a bot account can play a role as a credible source of news and advised many other health organizations with limited resources to use social bots for effective information dissemination [12].

Recently, research on news bots has expanded the scope to a chatbot, which is a conversational software program based on artificial intelligence and machine learning technologies (e.g., [19-25]). 
The major function of chatbots is to engage in direct interaction with audiences by exchanging questions and answers about news stories and obtaining feedback from audiences [26]. In doing so, chatbots simulate a human by using natural language and build a relationship with the audience [21-23,25]. Although some practical limitations and challenges in the current use of chatbots were reported, the development of chatbots is believed to have the potency for better engaging audiences with news stories and organizations by providing more interactive and personalized features of news [23]. Lately, the use of chatbots has been highlighted in the times of crisis, when a timely dissemination of accurate and trustworthy information is necessary [19,20,24], and Maniou and Veglis [20] showed that chatbots, as a reliable news source, can play an important role in the efficient delivery of accurate and useful information in a crisis, such as the pandemic of coronavirus disease (COVID-19).

Based on the aforementioned literature, key functions of news bots can be summarized into three categories-(a) news gathering and writing, (b) news distribution, and (c) interactions with audiencesalthough these are often inseparable from each other (for example, a Twitter bot sends out a tweet as soon as it is automatically created, and a chatbot delivers a customized list of news headlines to the audiences while interacting with them by receiving their questions and feedback, which can be used as new story ideas). Bots in the first category present the ability of automating news production from data collection, analysis, and inference to visualization [21]. Structural data, identified and handled by bots' algorithms, are incorporated with the narrative templates created by editors and journalists [26,27]. In this technology's infancy, bot-generated news stories had limited topics of coverage to data-based ones, such as sports (e.g., Olympic games), finance (e.g., stock analysis, earnings reports), weather forecasts, and election coverage, and the topics were soon extended to more complex areas, such as editorial articles [27,28]. As examples, 'Heliograf' by The Washington Post and 'Cyborg' by Bloomberg News are pioneering algorithmic programs in news writing, and 'Wibbitz' by USA Today provides a video-producing tool by converting text-based news articles into a script, along with relevant images or videos and synthesized narrations $[27,28]$. News bots in this category offer automatic variations in news stories for different platforms and help journalists in their newsgathering by assessing the credibility of incoming messages and alerting about anomalous bits of data (e.g., News Tracer by Reuters) $[27,28]$.

The second and third categories show more recent developments relating to news bots. Basically, bots in these areas facilitate news delivery to audiences through diverse online-based platforms (involving news selection processes to meet the needs and interests of audiences) and direct interactions with audiences [20]. BBC, a main news outlet in the U.K., provides good examples of utilizing news bots in their news distribution and interaction functions on major social media sites (e.g., Facebook, Twitter, and Telegram). According to BBC News Labs [29], BBC's Twitter bots focus on the automatic creation and distribution of graphics and have been used for presenting voting results during the EU Referendum and US presidential elections. The in-article chatbot, a conversational interface tool at the bottom of news stories, helps readers to find out more about the topic. In addition, through Facebook messenger, a quiz bot presents a series of multiple-choice questions about news stories, and the Mundo news bot leads subscribers to the official website by sending them a daily list of news headlines. The Mundo bot further enables them to request more stories or share stories with others within Facebook Messenger. With these news bots on social media platforms, BBC expects to reach new audiences, particularly those who are not visiting its official channels regularly and those who are not interested in traditional news presentation [29].

However, in contrast to these optimistic views, the vast majority of research on social bots has highlighted significant concerns over their malicious applications and negative consequences, such as the spread of misinformation and fake news, the manipulation of public opinion, and the influence on human decision and behavior (e.g., voting) [17,30-36]. The negative perspectives of social bots are based on the nature of computer algorithms that automatically create and replicate content online and interact with other users through mimicking human behaviors [32,37]. According to Keller and Klinger [17], social bots contribute to social media activities by (a) connecting a number of accounts and 
(b) magnifying the creation and spread of content through liking, sharing, retweeting, commenting, and so on. Studies have provided empirical evidence for the role of social bots in the spread of misinformation and manipulation of public perceptions and opinion by analyzing Twitter bot accounts regarding important political issues, such as the presidential election $[17,30,38]$ and the UK-EU referendum campaign [39]. The substantial impact that social bots can have is attributable to the high speed of automatic operations, such as content creation and distribution, liking and sharing, interactions with other users, and the algorithm that makes specific content look popular or trending $[30,37,40]$. Human users are prone to the manipulations and activities done by social bots because people tend to give more attention to what appears to be popular. Further, by interacting with social bots while the bots' artificial identities remain undisclosed, human users can misjudge the bot content's credibility and mistakenly rely on them $[19,24,26]$. In this regard, Everette et al. [41] summarized that bots automatically generate content to "inform, influence, and deceive" social media users.

\subsection{The Influence of Self-Efficacy on the Acceptance of News Bots}

With growing attention being paid to the potentially detrimental effects of social bots, the detection of bot accounts has been a major challenge for many researchers [32,40]. Although some bot accounts self-represent that they are automated accounts in their profile description, or by the creators' acknowledgment and open-source code, many of them are still uncovered, making them hard to identify from the user's or researcher's perspective. Among the 60 news bot accounts examined on Twitter by Lokot and Diakopoulos [10], around half did not represent their identity as a bot account or underlying algorithms. Many scholars argue that, as bots become more sophisticated at mimicking human behaviors based on state-of-the-art technology such as artificial intelligence and machine learning, it becomes a difficult task to discern bots from human accounts even for experienced researchers or computational algorithms [27,28,37,39,41]. Programs and services for bot detection (e.g., Bot or Not, Botometer) determine "botness" by examining hundreds of account features related with the user, its friends or network, and postings (e.g., timing, language) [10,37,39]. Lou et al. [33] explained that social bots are barely discernable as "some social bots behave in ways that cannot be distinguished by those of humans on an individual basis because automation is mixed with human behavior, or because their behaviors are driven by (or copied from) humans; automation is used mainly to replicate a behavior across many inauthentic accounts" (p. 2).

Given that the task of identifying bots is highly challenging, we assume that the impact of self-efficacy in discerning bot content can be a considerable predictor determining the acceptance of news bot. This is based on research showing that self-efficacy is a powerful determinant of attitudes and behavior in many learning contexts adopting Bandura's self-efficacy theory [42,43]. According to Bandura [44], self-efficacy is defined as the level of a person's confidence in their ability to successfully perform a behavior. Self-efficacy is known to be a strong influencer in motivating people to learn and master a skill as people with high self-efficacy are not only optimistic about mastering the skill but also less discouraged even when they seem to fail. This is because people with high self-efficacy possess high resilience; therefore, they treat encountering failures as challenges instead of threats and are more persistent in trying and learning the skill [45].

Applying Bandura's theory of self-efficacy in the social media context, Hocevar, Flanagin, and Metzger [46] utilized the concept of "social media self-efficacy" and showed that it was positively related to an individual's perceived trustworthiness of information on social media. Overall, people with high social media self-efficacy were found to evaluate information on social media more positively than those who are less efficacious. While the relationships between social media self-efficacy and perceived trustworthiness were found to be significant across three information domains (i.e., products, health, and news), the relationship was the strongest for product information compared to health information and news information.

Positive relationships between subject-specific self-efficacy and attitudes have been consistently found in previous studies (e.g., [47]). More recent studies have shown a significant and positive 
relationship between the two in terms of accepting new learning methods such as learning through tablet computers [48] or personal digital assistant (PDA) devices [49]. The studies showed that the more confidence one has in using technology, the more positively one accepts using technology in learning. Thus, correspondingly, we predicted a positive relationship between self-efficacy and an accepting attitude toward news bots as follows:

Hypothesis 1. The greater self-efficacy individuals have in identifying content from a bot, the more accepting they are of news bots.

According to Bandura [44], one's self-efficacy is built through the following sources: first-hand mastery experience, vicarious experience, performance feedback, and physiological and emotional states. Interestingly, it has been shown that repeated exposure to a task raises perceived self-efficacy regardless of whether it has actually been mastered. For example, after repeatedly watching how-to videos on YouTube, people tend to overestimate their ability to perform the same task although their actual performance has not improved after the video watching [50]. Self-efficacy regarding bots is assumed to develop based on first-hand mastery experience through which users successfully identify different content as originating from bots and also through vicarious experience where users observe and hear about bots from other sources, including the media. As self-efficacy is developed through repeated exposure and experience, we hypothesized there would be a positive relationship between self-efficacy and perception of bot news prevalence, as follows:

Hypothesis 2. The more individuals perceive the prevalence of social media news from bots, the greater self-efficacy they have in identifying content from a bot.

\subsection{The Influence of Perceived Prevalence on the Acceptance of News Bots}

While accurate detection or identification of bot accounts is not currently feasible, a previous study estimated that approximately $9 \%$ to $15 \%$ of active Twitter accounts are bots [16]. Another study by Bessi and Ferrara [30] reported that approximately 15\% of Twitter accounts under study were estimated to be bots, and 19\% of conversations were from bot accounts during the 2016 US presidential election. However, because there are no accurate and valid statistics, estimating the prevalence of bot content on social media is largely dependent on an individual user's subjective judgment.

In previous research, the prevalence of social bots has been often discussed in relation to negative outcomes, including the spread of fake news or misinformation and the manipulation of public opinion [35,51]. For example, by analyzing 389,569 articles from 120 low-credibility sites, Shao et al. [35] showed that bots actively spread content from low-credibility sources, especially at the early stage before it becomes popular. Furthermore, they found that some bot accounts on Twitter accounting for only $3 \%$ of the overall Twitter population were able to disseminate $30 \%$ of low-credibility articles to other Twitter users, and that this dissemination occurred within just two to ten seconds. The authors argued that this is partially due to the ability of bots to make certain information look popular and to target users with many followers. Similarly, it is widely accepted that computational propaganda from bot accounts on Twitter played a significant role in popularizing Trump's online following, consequently affecting the results of the 2016 presidential election [31,52]. In another study, bots boosted sentiments of alarmism and fear during and after the Catalan referendum in Spain by mimicking the trend of human users' emotional tweets [51].

Even though Vosoughi and colleagues [36] have shown that bots disseminate fake and true news equally and that humans actively convey misinformation more disproportionally than bots, there is a prevalent public opinion that attributes the creation and dissemination fake news online to bots [53]. In this regard, Reuter, Kaufhold, and Steinfort [54] argued that rumors, fake news, and social bots are the three key challenges in the age of social media. In addition, terms like "spambots" and "bimbots" have been often associated with the malicious application of bots by laypersons [12]. Given the strong associations with negatives, such as fake news, misinformation, manipulation, and spambots/bimbots, 
we proposed that people who perceive bot news prevalence would be less accepting of news bots and would evaluate social media news more negatively. Thus, we posited the following hypotheses:

Hypothesis 3. The more individuals perceive the prevalence of news from bots, the less accepting they will be of the news bots.

Hypothesis 4. The more individuals perceive the prevalence of news from bots, the more negatively they evaluate social media news.

Additionally, we posited an impact of news bot acceptance (which is presumably affected by self-efficacy and the perceived prevalence of bot news) on the evaluation of social media news in general. Relying on the unified theory of acceptance and use of the technology model, studies have shown that people accept a new technology when they recognize its value and when they have their performance expectancies met [55-57]. For example, Chao [55] showed that the performance expectancy that robots can provide consistent and dependable service to consumers predicted behavioral intentions to use robots. Yuan et al. [58] also showed that once people perceive the usefulness of technology, they report stronger intentions to use technology that then lead to actual repeated use. Thus, despite popular concerns over bots creating and disseminating disinformation and misinformation with a power of manipulating message flow on social media $[51,53,54]$, we assumed that people who accept the usage of news bots have recognized the bot's value and positive attributes, such as its usefulness and credibility. Previous studies have also shown that news contents from bots are perceived as more credible, objective, and informative by news audiences, compared to those by human journalists $[59,60]$. After interacting with news bots, people perceived bot-created messages to be unpretentious, optimistic, and helpful [19]. Thurman et al. [61] showed that online news audiences preferred news story selection by algorithms, mainly based on their past news consumption, compared to that by editors, and they tended to perceive algorithmic selection to be less affected by political bias and other contaminations of news media. Additionally, given that a significant portion of social media news originates from bots $[16,30]$, we argue that positive attitudes toward news bots will be transferred to overall social media news evaluations. Therefore, we hypothesized that those who accept news bots would be more prone to evaluate news on social media positively.

Hypothesis 5. The more acceptable individuals find news bots, the more positively they will evaluate social media news.

\subsection{The Influence of Demographics}

Studies have examined the impact of demographic factors such as age, gender, income, and education level on social media news use, trust in social media news, and efficacy in verifying false information on social media. Glynn and colleagues [62] showed that young, female, and technologically savvy users of Facebook used the site for news-related purposes more than their counterparts. Warner-Søderholm et al. [63] presented a similar trend in predicting trust in social media news showing younger, female users of social media are more inclined to trust news on social media. In another study, level of income positively impacted the likelihood of perceived self-efficacy in recognizing misinformation, whereas education level negatively impacted perceived efficacy. Less-educated respondents had more perceived self-efficacy in recognizing misinformation [64]. Although there are many studies demonstrating the impact of demographic factors on different aspects of social media use, little empirical evidence of demographic factors affecting perceptions regarding news bots can be found. Because perceived prevalence, self-efficacy in identifying bot news, acceptance of news bots, and social media news evaluation are all susceptible to demographic factors, we proposed the following research question in order to explore how demographic variables affect the four endogenous variables:

RQ: How are the individual demographics (i.e., age, gender, education level) related to self-efficacy in identifying bot content, the perceived prevalence of bot news, the acceptance of news bots, and overall evaluation of social media news? 


\section{Materials and Methods}

\subsection{Procedure and Sample}

The dataset was obtained from the 2018 American Trends Survey, which was designed and conducted by Pew Research Center and GfK Custom Research, LLC. The American Trends Panel (ATP) is a nationwide probability-based panel, consisting of US adult samples aged 18 years or over. This study utilized the Wave 37 survey that was conducted online (accessed through either PC or mobile devices) between 30 July and 12 August, 2018. A postcard was mailed to participants in advance to notify them about the survey and invite them to take part. The online survey link was sent via email or short message service (if consented to in advance) to 5475 valid ATP members. With up to four reminders to nonresponding samples, a total of 4581 respondents completed the survey, which resulted in the response rate of $83.7 \%$ with a margin of error of \pm 2.39 (95\% confidence interval). A monetary incentive was awarded for participation. The detailed survey procedure and original dataset are available at the official website of the Pew Research Center (https://www.pewresearch.org/methods/dataset/american-trends-panel-wave-37/).

Given the high news dependency on social media [2-4], this study focused on social media users who use news via diverse social media sites. The current dataset confirmed that a significant portion of respondents were using social media for news either often $(n=882,19.3 \%)$ or sometimes $(\mathrm{n}=1273,27.8 \%)$. By considering those who consume news through social media, this study aimed to investigate the influence of self-efficacy in identifying content from a bot and perception of its prevalence on the acceptance of news bots, which may allow the evaluation of social media news in general. In doing so, this study did not limit its scope to a specific social media site or a specific demographic group. However, as part of the analysis, demographic differences were also examined in terms of their potential impacts on the variables proposed regarding news bots and their content in social media.

From the original dataset of 4581 cases, 1402 respondents (30.6\%) reported that they had never obtained news from social media sites and were thus excluded from analysis. Additionally, 810 respondents were excluded because they had heard nothing at all about social media bots and were asked to skip the survey questions about bots and content from a bot in social media. Among the remaining 2369 respondents, cases with at least one missing value in the variables of the current analysis were screened and removed for a rigorous model testing. As a result, responses collected from 2270 social media users were used for further analysis.

In the screened dataset, there was no significant difference in the number of female $(48.5 \%)$ and male (51.5\%) respondents, and their ages ranged from 18 to $29(15.1 \%), 30$ to $49(38.6 \%), 50$ to 64 $(27.8 \%)$, and over $65(18.5 \%)$. The majority of respondents were White $(77.1 \%)$, followed by Black or African-American (9.2\%), mixed (4.4\%), and Asian or Asian-American (3.9\%). Regarding education level, $12.5 \%$ were high school graduates or lower, $28.3 \%$ had some college experience with no degree, and $59.2 \%$ had completed college or had postgraduate education. The respondents in the subset used for analysis were slightly younger and more educated compared to the original dataset of 4581 respondents $(18-29=9.7 \%, 30-49=29.2 \%, 50-64=31.6 \%$, and $65+=29.4 \%$; high school graduates or lower $=15.3 \%$, some college experience $=29.9 \%$, and a college degree or higher $=54.4 \%$ ).

\subsection{Survey Instrument}

The question items were included as part of a large-scale survey examining American trends. A designated section on social media bots started with an introduction as follows: "Now we're going to ask you a few questions about social media bots. A social media bot is an account that operates on its own, without human involvement, to post and do other activities on social media sites". Afterward, respondents were asked how much they had heard about social media bots, and those who reported "nothing at all" moved to the next section without receiving the follow-up questions about social bots. The remaining participants were asked about their self-efficacy in rating how confident they 
were in their ability to identify whether a post on social media comes from a bot $(1=$ not at all confident to $4=$ very confident). The perceived prevalence was measured using the question "Of all the news that Americans get from social media sites, how much do you think gets to them from bots" $(1=$ not at all to $4=$ a great deal), and acceptance was measured by asking whether or not a news organization's use of bots is acceptable in creating and posting news $(1=$ acceptable, $0=$ not acceptable).

For social media news evaluation, two question items were utilized to measure how respondents evaluated social media news and respondents rated (a) how helpful it is in better understanding current events on a one-to-three scale, and (b) overall, how accurate they expect it to be $(1=$ largely accurate or $0=$ largely inaccurate). These two questions were given only to those obtaining news from social media sites (such as Facebook, Twitter, or Snapchat). At the end of the survey, the major demographics of respondents were measured, including age $(1=18-29,2=30-49,3=50-64,4=65$ or over), gender ( $1=$ male, $2=$ female $)$, race $(1=$ White, $2=$ Black or African American, $3=$ Asian or Asian-American, $4=$ mixed, $5=$ other $)$, and education level ( $1=$ HS graduate or less, $2=$ some college, $3=$ college graduate or higher). Some variables were re-categorized or reverse-coded from the original dataset for analytic purposes.

\section{Results}

First, descriptive statistics and bivariate correlations among observed variables were calculated and are shown in Table 1. Overall, respondents showed considerable self-efficacy in identifying content from a bot $(M=2.423, S D=0.816)$ and were aware of bot news on social media $(M=3.004, S D=0.574)$. The proportion of respondents who accepted news bots (53.0\%) was slightly higher than that of their counterparts $(47.0 \%)$. While the helpfulness of social media news was mostly perceived positively $(3=36.3 \% ; 2=50.0 \% ; 1=13.7 \% ; M=2.226, S D=0.670)$, more than half of the respondents $(59.5 \%)$ perceived it as largely inaccurate. The level of self-efficacy was significantly correlated with perceived prevalence of bot news on social media $(r=0.216, p<0.001)$ and acceptance of news bots $(r=0.216$, $p<0.05)$. However, the perceived prevalence of bot news was not related to acceptance $(r=0.216$, $p>0.05$ ). The two measures of social media news evaluation (i.e., helpfulness and accuracy) were positively associated $(r=0.346, p<0.001)$. Among the correlations, negative relationships were found between the prevalence of bot news and the two news evaluation measures (accuracy: $r=-0.153$, $p<0.001$; helpfulness: $r=-0.073, p<0.01$ ).

Table 1. Correlation coefficients and descriptive statistics.

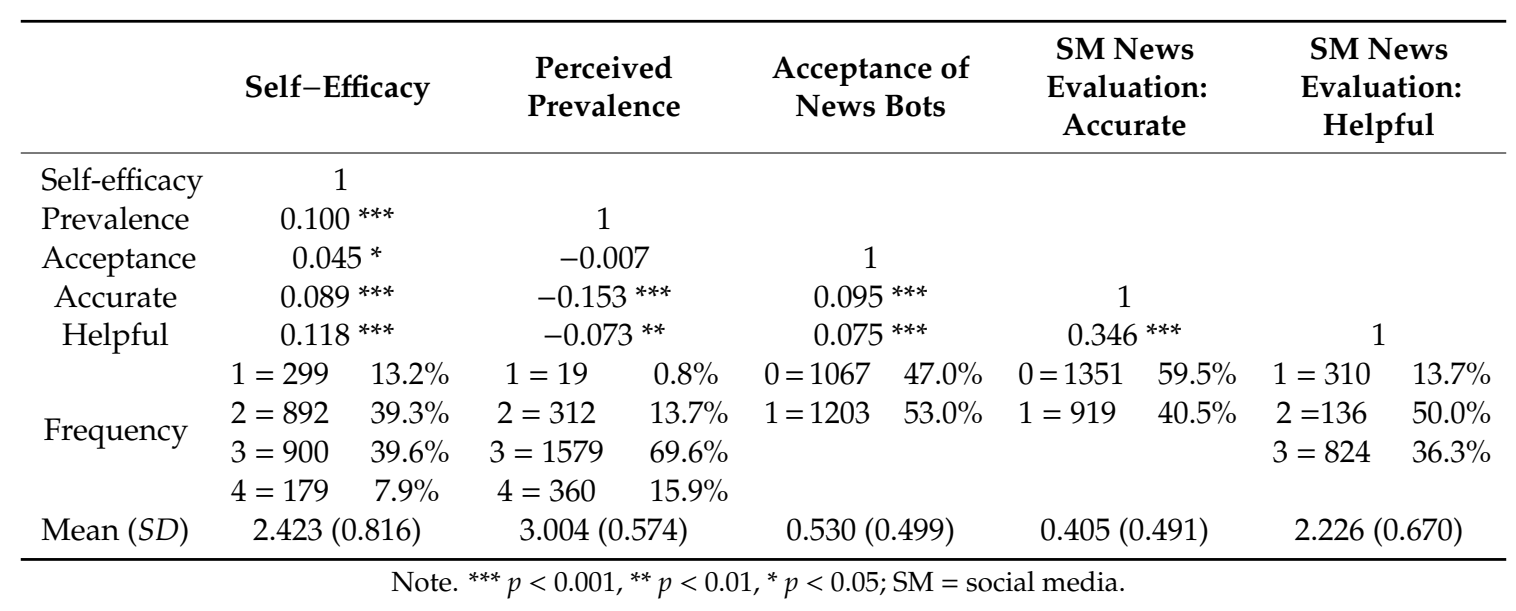

Utilizing the AMOS program, research hypotheses were tested by structural equation modeling (SEM) with the maximum likelihood estimation method. As Figure 1 shows, the proposed model showed an overall satisfactory model fitness, represented by several indices $\left(\chi^{2}{ }_{(9)}=63.481, p<0.001\right.$; $\chi^{2} / d f=7.053 ; \mathrm{GFI}=0.993, \mathrm{AGFI}=0.973 ; \mathrm{NFI}=0.891 ; \mathrm{CFI}=0.901 ; \mathrm{RMSEA}=0.052 ;$ Std. $\left.\mathrm{RMR}=0.014\right)$. In addition, significant paths in the model indicated that four out of the five hypotheses $(\mathrm{H} 1, \mathrm{H} 2$, 
$\mathrm{H} 4$, and H5) were supported (See Table 2). Individuals perceived news organizations' use of bots as acceptable as they have high self-efficacy in identifying content from a bot $(\mathrm{H} 1: \beta=0.463, p<0.001$; $B=0.650, S E=0.083$ ), which was affected by the perceived prevalence of bot news on social media $(\mathrm{H} 2: \beta=0.106, p<0.001 ; B=0.151, S E=0.029)$. However, the perceived prevalence of bot news did not significantly influence an individual's acceptance of using bots in news organizations (H3: $\beta=-0.012$, $p>0.05 ; B=-0.011, S E=0.018)$, but it had a direct negative influence on the evaluation of social media news (H4: $\beta=-0.198, p<0.001 ; B=-0.127, S E=0.017$ ). In other words, those who perceive that bot news is more prevalent on social media tended to evaluate social media news more negatively. Finally, acceptance of using news bots was associated with the evaluation of social media news. More specifically, the more individuals think it is acceptable for news organizations to use bots, the more positively they evaluate social media news (H5: $\beta=0.135, p<0.001 ; B=0.099, S E=0.020$ ).

The research question asked how an individual's demographic factors (i.e., age, gender, education) may be related to the major variables of this study, and a few demographic differences were found in the SEM results. Respondents who were males $(\beta=-0.112, p<0.001 ; B=-0.183, S E=0.033)$, younger $(\beta=-0.157, p<0.001 ; B=-0.133, S E=0.017)$, and less educated $(\beta=-0.049, p<0.05$; $B=-0.056, S E=0.024)$ showed greater self-efficacy than their counterparts. Females perceived greater prevalence of bot news on social media $(\beta=0.054, p<0.01 ; B=0.062, S E=0.024)$ compared to males, but age and education were not associated with how individuals perceived the prevalence of bot news. The acceptance of using bots in news organizations was influenced only by education level, with those who had more education being more accepting of news bots $(\beta=0.050, p<0.05 ; B=0.036, S E=0.015)$. For social media news, older respondents were more likely to evaluate it negatively than younger respondents $(\beta=-0.082, p<0.01 ; B=-0.032, S E=0.010)$. There was a tendency for females and the less-educated to evaluate social media news more positively than their counterparts at a marginal level of statistical significance (gender: $\beta=0.047, p=0.078 ; B=0.034, S E=0.019$, and education: $\beta=-0.047$, $p=0.073 ; B=-0.025, S E=0.014)$.

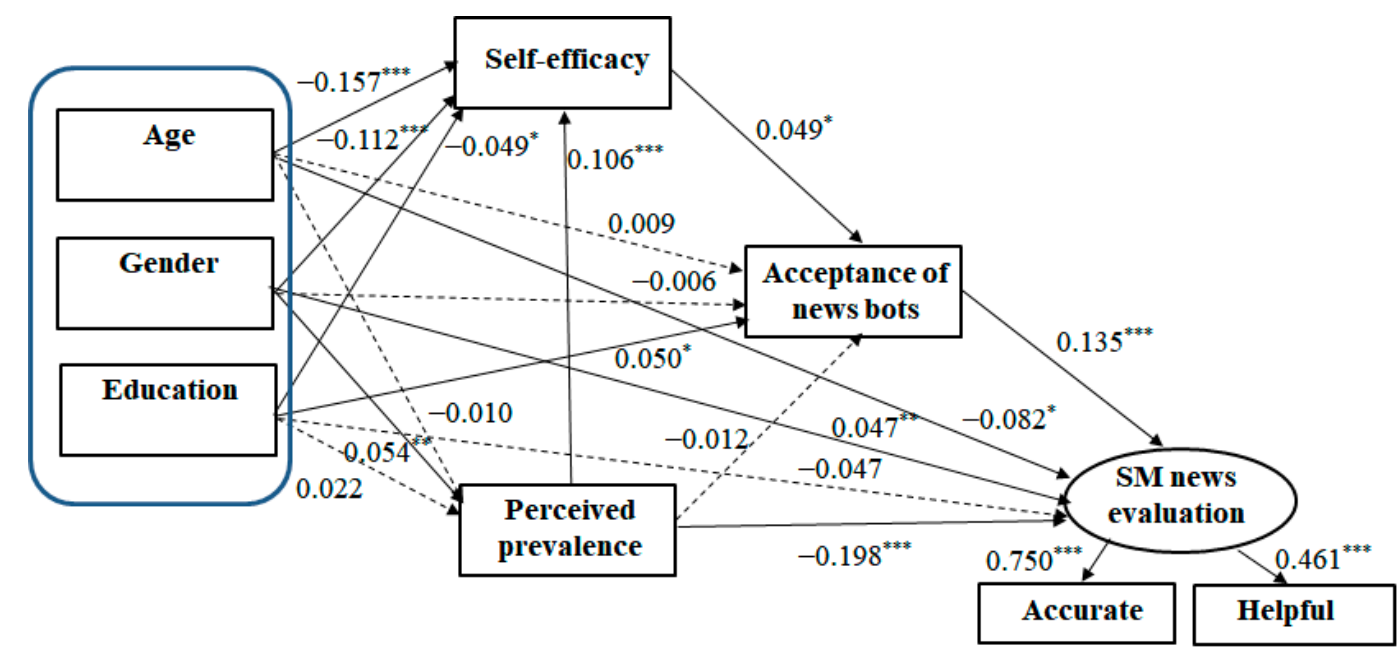

$$
\begin{aligned}
& \chi_{(9)}^{2}=63.481, p<0.001 ; \chi^{2} / d f=7.053 \\
& \text { GFI }=0.993, \mathrm{AGFI}=0.973 ; \\
& \mathrm{NFI}=0.891 ; \mathrm{CFI}=0.901 ; \\
& \mathrm{RMSEA}=0.052 ; \text { Std. } \mathrm{RMR}=0.014
\end{aligned}
$$

Figure 1. Structural equation modeling results. Note. ${ }^{* * *} p<0.001,{ }^{* *} p<0.01,{ }^{*} p<0.05 ; \mathrm{SM}=$ social media. 
Table 2. Path estimates in the structural model.

\begin{tabular}{cccccccc}
\hline & & & $\mathcal{B}$ & $\boldsymbol{B}$ & $\boldsymbol{S} . \boldsymbol{E}$. & $\boldsymbol{C} . \boldsymbol{R}$. & $p$ \\
\hline Acceptance & $\leftarrow$ & Self-efficacy & 0.049 & 0.030 & 0.013 & 2.288 & 0.022 \\
Acceptance & $\leftarrow$ & Prevalence & -0.012 & -0.011 & 0.018 & -0.576 & 0.564 \\
Self-efficacy & $\leftarrow$ & Prevalence & 0.106 & 0.151 & 0.029 & 5.168 & $<0.001$ \\
SM news evaluation & $\leftarrow$ & Acceptance & 0.135 & 0.099 & 0.020 & 5.047 & $<0.001$ \\
SM news evaluation & $\leftarrow$ & Prevalence & -0.198 & -0.127 & 0.017 & -7.304 & $<0.001$ \\
Prevalence & $\leftarrow$ & Age & -0.010 & -0.006 & 0.013 & -0.463 & 0.643 \\
Prevalence & $\leftarrow$ & Gender & 0.054 & 0.062 & 0.024 & 2.561 & 0.010 \\
Prevalence & $\leftarrow$ & Education & 0.022 & 0.018 & 0.017 & 1.060 & 0.289 \\
Self-efficacy & $\leftarrow$ & Age & -0.157 & -0.133 & 0.017 & -7.661 & $<0.001$ \\
Self-efficacy & $\leftarrow$ & Gender & -0.112 & -0.183 & 0.033 & -5.458 & $<0.001$ \\
Self-efficacy & $\leftarrow$ & Education & -0.049 & -0.056 & 0.024 & -2.376 & 0.018 \\
Acceptance & $\leftarrow$ & Age & 0.009 & 0.005 & 0.011 & 0.415 & 0.678 \\
Acceptance & $\leftarrow$ & Gender & -0.006 & -0.006 & 0.021 & -0.286 & 0.775 \\
Acceptance & $\leftarrow$ & Education & 0.050 & 0.036 & 0.015 & 2.405 & 0.016 \\
SM news evaluation & $\leftarrow$ & Age & -0.082 & -0.032 & 0.010 & -3.115 & 0.002 \\
SM news evaluation & $\leftarrow$ & Gender & 0.047 & 0.034 & 0.019 & 1.759 & 0.078 \\
SM news evaluation & $\leftarrow$ & Education & -0.047 & -0.025 & 0.014 & -1.791 & 0.073 \\
Accurate & $\leftarrow$ & SM news evaluation & 0.750 & 1.000 & & & \\
Helpful & $\leftarrow$ & SM news evaluation & 0.461 & 0.839 & 0.144 & 5.826 & $<0.001$ \\
\hline
\end{tabular}

Note. SM = social media. Arrows indicate hypothesized paths between the variables.

\section{Discussion}

While the application of bots has recently become popular in news organizations (from news production and distribution to interactions with news audiences), there are still mixed views regarding the impact of news bots on news organizations, audiences, and society $[10,17,32]$. Under these circumstances, a national survey released by Pew Research Center [15] showed that the number of respondents who were accepting vs. not accepting of news bots was nearly balanced in the US. This triggered our attention to the current research agenda and led to the question about user perspectives of news bots. In particular, this study aimed to examine what affects the acceptance of the use of bots by news organizations and suggested two potential predictors: self-efficacy and perceived prevalence. An analysis of the national survey dataset of social media news users in the US showed that individuals were more likely to accept news bots when they had greater self-efficacy in identifying content from a bot. In addition, although the greater perception of bot news prevalence did not directly affect acceptance, it had an indirect influence on acceptance by strengthening one's self-efficacy. Moreover, this acceptance resulted in the evaluation of social media news in general, with those who accepted the use of news bots tending to consider social media news more positively (i.e., more accurate and helpful) than those who did not. However, greater awareness of bot news prevalence on social media induced a negative evaluation of social media news.

Some findings from this study require further in-depth discussion. First, an individual's self-efficacy in identifying content from a bot was a key factor that increased the acceptance of news organizations' bot usage, which, in turn, led to a more positive evaluation of social media news in general. Additionally, the level of self-efficacy was somewhat dependent on demographics, being higher among those who were males, younger, and less educated. As self-efficacy is a subjective evaluation of confidence, it is uncertain whether respondents really had an ability to identify bot accounts, and thus, their ability may have been over- or under-estimated. Nevertheless, it is clear that, regardless of individual properties, confidence can be increased when a clear identifier is provided for bot accounts and the contents from them. In this regard, Montal and Reich [11] recommended a crediting policy that requires a clear byline of bot-created news and full disclosure of the algorithmic nature of the content. The results of the current study imply that a clear sign for bot accounts and their contents would help social media news users' self-efficacy in their identification ability and acceptance 
of news bots and ultimately lead to a more positive evaluation of social media news in general. As the self-efficacy theory argues [44], both mastery and vicarious experience with bots will strengthen social media users' self-efficacy in identifying bots. A clear identifier for news bots is expected to increase the transparency of news organizations, news production processes, and their contents. Presumably, it will satisfy the needs of social media news users, increase their news literacy, and help in improving public support and interest in social media news. As Lokot and Diakopoulos [10] argue, if news bots are not discernable on social media as they currently are, journalistic transparency and the credibility of automated news will be inevitably threatened. Institutional changes regarding news bots, such as verification processes and crediting policies for the content from news bots, will be a primary task for news organizations as well as social media platforms. News will be continuously circulated and accessed through social media, and news organizations are expected to have the benefits of positive evaluation of their news and sustainability of themselves by accommodating these institutional changes. The institutional changes can function as news literacy education where news organizations empower individual audiences by helping them build knowledge about social media bots and news bots.

We proposed that the perceived prevalence of bot news would be another predictor of the acceptance of news bots and hypothesized a negative relationship, but this was not fully supported. The negative relationship was posited based on the extensive scholarly work on fake news, misinformation on social media, and negative perceptions associated with social bots, such as spambots $[12,17,30-36]$. However, this insignificant relationship implies that there was another drive to a positive direction, the so-called "Hollywood Robot Syndrome". The term was coined by Sundar, Waddell, and Jung [65], who showed that past exposure to the concept of robots through the media decreased anxiety toward robots. Specifically, people who were able to recall more movies that featured robots reported lower anxiety toward using robots in life compared to people who could not recall movies as well [65]. Afterward, Waddell [66] also applied Hollywood Robot Syndrome to the context of "robot-written" news articles. In an experiment, the participants who could recall a robot from past media, such as a film or television show, evaluated a robot-written news article more positively than those who could not recall a robot from the media [66]. These studies consistently show that people's resistance toward a new technology diminishes as they become more exposed to it and experience it more, and correspondingly, findings imply a positive influence of greater awareness of bot news on the attitude toward it. Thus, the insignificant relationship may be the result of both positive and negative directional forces of the perceived prevalence of bot news on its acceptance. However, it appears that the perceived prevalence of bot news was directly associated with the negative evaluation of social media news. The results again confirm that the engagement of news bots may be considered negative (e.g., through the spread of fake news or misinformation) in the minds of social media users, at least to a certain degree, as shown in previous studies (e.g., [30-33,35,36]). Thus, it remains an important task to examine and overcome the negative connotations social media bots and news bots bear in the mindsets of social media users. Further studies are required to examine both the Hollywood Robot Syndrome [65] and the strength of those negative connotations in a single study to better understand the underlying psychological mechanism surrounding the acceptance of news bots.

Social media has become a major source of news for many news audiences over the past few years [2-4]. Despite its popularity, many still have concerns over social media news in terms of its accuracy, bias, and low quality $[3,4,54]$. Thus, for sustainable news business, it is necessary to improve the quality of social media news and the trustworthiness of social media as a credible news channel. The results of this study showed that acceptance of news bots was related to the positive evaluation of social media news, and thus, increasing acceptance can be one way to achieve this goal. The current study also identified demographic differences in the key variables. For example, for the perceived prevalence of bot news, female respondents thought bot news was more prevalent on social media compared to male counterparts. As females are more active users of social media when it comes to news consumption [62], it is plausible that greater exposure to news on social media may have led them to perceive that more news has been provided by a bot. In addition, respondents with a 
higher education level were more likely to accept news organizations' bot usage than those with a lower education level. The Gallup/Knight Foundation Survey found that college graduates had higher trust in news media than non-college graduates. When determining which news sources to trust, more educated individuals, such as college graduates, cared more about a news organization's history and reputation compared to the less-educated [67]. Therefore, we speculate that a higher education level leads to greater trust in legitimate news media, resulting in a more lenient attitude toward news organizations' bot usage in creating and disseminating news.

It is somewhat unintuitive that respondents who are less educated perceived higher self-efficacy in identifying content from a bot, although this finding aligns with Khan and Idris's [64] study showing that less-educated respondents had more perceived self-efficacy in recognizing misinformation. One possible explanation for this is that people with greater educational experience possess greater knowledge about news bots and acknowledge that it is very hard to detect content arising from bots and therefore report low self-efficacy. Self-efficacy is the self-assessment of performing a certain task and is not necessarily associated with actual efficacy. Therefore, it is possible that people with less educational experience tend to overestimate their self-efficacy in recognizing bot news. In addition, this finding may have been influenced by the selection of respondents in this study (i.e., social media users who obtain news from social media sites and had already heard of social media bots). Indeed, a substantial portion of respondents (1317 out of 4581 respondents) reported that they have never heard of social media bots and thus did not receive the follow-up questions about social media bots. The ratio of 'not-heard' respondents was highest among those who were high school graduates or lower $(47.4 \%)$, followed by those with some college experience $(33.1 \%)$ and college graduates or higher (21.3\%). Presumably, the less-educated respondents who were included in the analysis may have special interests in and adequate knowledge about social media bots, and this may result in greater self-efficacy among the respondents with less educational experience. Thus, findings should be interpreted cautiously as the results may be different if those who have never heard of bot news are considered as being low in self-efficacy.

\section{Conclusions}

Given the increasing use of social media for news, this study focused on the social media news users' perspectives of news bots and content from a bot. This study relied on the strong belief that a deeper understanding of these news audiences would be imperative for sustainable news business in the current social media environment. We found a significant role for self-efficacy, as the more people thought that they were capable of detecting content from a bot, the more they accepted news bots. In addition, the perceived prevalence of news from bots did not directly predict the acceptance of news bots but indirectly predicted it through self-efficacy. This study also showed the acceptance of news bots was significantly related to positive evaluation of social media news.

Among the many insights that can be drawn from these results, it is noteworthy that, by clearly indicating that the contents are from a bot, news organizations can benefit from a greater public acceptance of news bots and, ultimately, public interest in social media news. Increased public support and interest in news bots and social media news will be advantageous for the sustainability of news organizations while they are making necessary policy changes about how to utilize and credit bots in their news production and dissemination. Furthermore, such institutional changes would also strengthen their transparency and enhance the news literacy of audiences, and these ultimately would help to improve the sustainability of news business suffering from declining readership and media credibility.

Despite the considerable contribution of this study to the existing literature, it also has limitations that are mainly due to the limited set of measurements in the dataset. Most variables were either singleor two-item measures. For example, the acceptance of news bots was measured as a dichotomous variable (acceptable vs. not acceptable). In addition, only two variables (self-efficacy and the perceived prevalence of bot news on social media) were included in the model as antecedents of acceptance 
of news bots. However, because self-efficacy is inherently a subjective evaluation, a more objective measure, such as knowledge about social media bots, would be a valuable addition in predicting acceptance of news bots and evaluation of social media news. Such speculation is supported by Stocking and Sumida [15], who found that those who have heard more about social media bots were less supportive about the use of social media bots in many circumstances. In addition, it is worth noting that news bots are rapidly evolving and have substantially affected a wide range of news production and other procedures in newsrooms over the past couple of years $[20,26,28]$. Accordingly, the number of individuals who use social media for news while being aware of news bots would be much greater today compared to the point of data collection of the current study (mid-2018). Thus, future studies are necessary in order to pursue the current state and ever-changing environment of news media and their users. Lastly, the frequency of social media site visits or preferences toward social media as a news source compared to other online and offline news outlets may have a significant impact on the perceptions of news bots and social media news in general. Future studies will provide richer insights if these issues are comprehensively considered.

Author Contributions: Conceptualization, H.H. and H.J.O.; Data curation, H.H.; Formal analysis, H.H.; Investigation, H.J.O.; Validation, H.H. and H.J.O.; Visualization, H.H.; Writing-original draft, H.H. and H.J.O.; Writing - review and editing, H.H. and H.J.O. All authors have read and agreed to the published version of the manuscript.

Funding: This research received no external funding.

Conflicts of Interest: The authors declare no conflict of interest.

\section{References}

1. Wu, S.; Tandoc, E.C.; Salmon, C.T. When Journalism and Automation Intersect: Assessing the Influence of the Technological Field on Contemporary Newsrooms. J. Pract. 2019, 13, 1238-1254. [CrossRef]

2. Nielsen, R.K.; Cornia, A.; Kalogeropoulos, A. Challenges and Opportunities for News Media and Journalism in an Increasingly Digital, Mobile and Social Media Environment; Reuters Institute for the Study of Journalism: Oxford, UK, 2016. Available online: https://ssrn.com/abstract=2879383 (accessed on 1 June 2020).

3. Shearer, K.; Matsa, K.E. News Use across Social Media Platforms; Pew Research Center: Washington, DC, USA, 2018. Available online: https://www.journalism.org/2018/09/10/news-use-across-social-mediaplatforms-2018/ (accessed on 11 June 2020).

4. Shu, K.; Mahudeswaran, D.; Wang, S.; Lee, D.; Liu, H. FakeNewsNet: A Data Repository with News Content, Social Context, and Spatiotemporal Information for Studying Fake News on Social Media. Big Data 2020, 8, 171-188. [CrossRef]

5. Boczkowski, P.J.; Mitchelstein, E.; Matassi, M. News Comes across When I'm in a Moment of Leisure: Understanding the Practices of Incidental News Consumption on Social Media. New Media Soc. 2018, 20, 3523-3539. [CrossRef]

6. An, J.; Quercia, D.; Crowcroft, J. Fragmented Social Media: A Look into Selective Exposure to Political News Categories and Subject Descriptors. In Proceedings of the 22nd International Conference on World Wide Web, Rio de Janeiro, Brazil, 13-17 May 2013; pp. 51-52.

7. Cinelli, M.; Brugnoli, E.; Schmidt, A.L.; Zollo, F.; Quattrociocchi, W.; Scala, A. Selective Exposure Shapes the Facebook News Diet. PLoS ONE 2020, 15, e0229129. [CrossRef]

8. Messing, S.; Westwood, S.J. Selective Exposure in the Age of Social Media: Endorsements Trump Partisan Source Affiliation When Selecting News Online. Communic. Res. 2012, 41, 1042-1063. [CrossRef]

9. Jung, J.; Song, H.; Kim, Y.; Im, H.; Oh, S. Intrusion of Software Robots into Journalism: The Public's and Journalists' Perceptions of News Written by Algorithms and Human Journalists. Comput. Hum. Behav. 2017, 71, 291-298. [CrossRef]

10. Lokot, T.; Diakopoulos, N. News Bots: Automating News and Information Dissemination on Twitter. Digit. J. 2016, 4, 682-699. [CrossRef]

11. Montal, T.; Reich, Z. I, Robot. You, Journalist. Who Is the Author? Authorship, Bylines and Full Disclosure in Automated Journalism. Digit. J. 2017, 5, 829-849. [CrossRef] 
12. Edwards, C.; Edwards, A.; Spence, P.R.; Shelton, A.K. Is That a Bot Running the Social Media Feed? Testing the Differences in Perceptions of Communication Quality for a Human Agent and a Bot Agent on Twitter. Comput. Hum. Behav. 2014, 33, 372-376. [CrossRef]

13. Deuze, M. What Is Journalism? Professional Identity and Ideology of Journalists Reconsidered. Journalism 2005, 6, 442-464. [CrossRef]

14. Diakopoulos, N. Algorithmic Accountability: Journalistic Investigation of Computational Power Structures. Digit. J. 2015, 3, 398-415. [CrossRef]

15. Stocking, G.; Sumida, N. Social Media Bots Draw Public's Attention and Concern; Pew Research Center: Washington, DC, USA, 2018. Available online: https://www.journalism.org/2018/10/15/social-media-botsdraw-publics-attention-and-concern/ (accessed on 2 May 2020).

16. Varol, O.; Ferrara, E.; Davis, C.A.; Menczer, F.; Flammini, A. Online Human-Bot Interactions: Detection, Estimation, and Characterization. In Proceedings of the International AAAI Conference on Web and Social Media (ICWSM), Montreal, QC, Canada, 15-18 May 2017; pp. 280-289. Available online: https: //arxiv.org/abs/1703.03107 (accessed on 10 June 2020).

17. Keller, T.R.; Klinger, U. Social Bots in Election Campaigns: Theoretical, Empirical, and Methodological Implications. Political Commun. 2019, 36, 171-189. [CrossRef]

18. Zheng, Y.; Zhong, B.; Yang, F. When Algorithms Meet Journalism: The User Perception to Automated News in a Cross-Cultural Context. Comput. Hum. Behav. 2018, 86, 266-275. [CrossRef]

19. Ford, H.; Hutchinson, J. Newsbots That Mediate Journalist and Audience Relationships. Digit. J. 2019, 7, 1013-1031. [CrossRef]

20. Maniou, T.A.; Veglis, A. Employing a Chatbot for News Dissemination during Crisis: Design, Implementation and Evaluation. Future Internet 2020, 12, 109. [CrossRef]

21. Veglis, A.; Maniou, T.A. Embedding a Chatbot in a News Article: Design and Implementation. In Proceedings of the 23rd Pan-Hellenic Conference on Informatics (PCI), Nicosia, Cyprus, 28-30 November 2019; pp. 169-172. [CrossRef]

22. Veglis, A.; Maniou, T.A. Chatbots on the Rise: A New Narrative in Journalism. Stud. Media Commun. 2019, 7, 1-6. [CrossRef]

23. Jones, B.; Jones, R. Public Service Chatbots: Automating Conversation with BBC News. Digit. J. 2019, 7, 1032-1053. [CrossRef]

24. Piccolo, L.S.G.; Roberts, S.; Iosif, A.; Harith, A. Designing Chatbots for Crises: A Case Study Contrasting Potential and Reality. In Proceedings of the 32nd International BCS Human Computer Interaction Conference (HCI), Belfast, UK, 4-6 July 2018; pp. 1-10. [CrossRef]

25. Radziwill, N.M.; Benton, M.C. Evaluating Quality of Chatbots and Intelligent Conversational Agents. arXiv 2017, arXiv:1704.04579. Available online: https://arxiv.org/abs/1704.04579 (accessed on 1 August 2020).

26. Lewis, S.C.; Guzman, A.L.; Schmidt, T.R. Automation, Journalism, and Human-Machine Communication: Rethinking Roles and Relationships of Humans and Machines in News. Digit. J. 2019, 7, 409-427. [CrossRef]

27. Keohane, J. What News-Writing Bots Mean for the Future of Journalism. Wired, 16 February 2017. Available online: https://www.wired.com/2017/02/robots-wrote-this-story/(accessed on 2 August 2020).

28. Peiser, J. The Rise of the Robot Reporter. The New York Times, 5 February 2019. Available online: https: //www.nytimes.com/2019/02/05/business/media/artificial-intelligence-journalism-robots.html(accessed on 3 August 2020).

29. BBC News Labs. Available online: https://bbcnewslabs.co.uk/projects/bots/ (accessed on 2 August 2020).

30. Bessi, A.; Ferrara, E. Social Bots Distort the 2016 U.S. Presidential Election Online Discussion. First Monday 2016, 21. [CrossRef]

31. Bovet, A.; Makse, H.A. Influence of Fake News in Twitter during the 2016 US Presidential Election. Nat. Commun. 2019, 10, 1-14. [CrossRef] [PubMed]

32. Ferrara, B.Y.E.; Varol, O.; Davis, C.; Menczer, F.; Flammini, A. The Rise of Social Bots. Commun. ACM 2016, 59, 96-104. [CrossRef]

33. Lou, X.; Flammini, A.; Menczer, F. Manipulating the Online Marketplace of Ideas; Technical Report; 2020. Available online: https://arxiv.org/abs/1907.06130 (accessed on 13 June 2020).

34. Ross, B.; Pilz, L.; Cabrera, B.; Brachten, F.; Neubaum, G.; Stieglitz, S. Are Social Bots a Real Threat? An Agent-Based Model of the Spiral of Silence to Analyse the Impact of Manipulative Actors in Social Networks. Eur. J. Inf. Syst. 2019, 28, 394-412. [CrossRef] 
35. Shao, C.; Ciampaglia, G.L.; Varol, O.; Yang, K.C.; Flammini, A.; Menczer, F. The Spread of Low-Credibility Content by Social Bots. Nat. Commun. 2018, 9, 4787. [CrossRef] [PubMed]

36. Vosoughi, S.; Roy, D.; Aral, S. The Spread of True and False News Online. Science 2018, 359, $1146-1151$. [CrossRef]

37. Yang, K.; Varol, O.; Davis, C.A.; Ferrara, E.; Flammini, A.; Menczer, F. Arming the Public with Artificial Intelligence to Counter Social Bots. Hum. Behav. Emerg. Technol. 2019, 1, 48-61. [CrossRef]

38. Ferrara, E. Disinformation and Social Bot Operations in the Run up to the 2017 French Presidential Election. First Monday 2017, 22. [CrossRef]

39. Duh, A.; Rupnik, M.S.; Korošak, D. Collective Behavior of Social Bots Is Encoded in Their Temporal Twitter Activity. Big Data 2018, 6, 113-123. [CrossRef]

40. Lazer, D.M.J.; Baum, M.A.; Benkler, Y.; Berinsky, A.J.; Greenhill, K.M.; Menczer, F.; Metzger, M.J.; Nyhan, B.; Pennycook, G.; Rothschild, D.; et al. The Science of Fake News. Science 2018, 359, 1094-1096. [CrossRef]

41. Everett, R.M.; Nurse, J.R.C.; Erola, A. The Anatomy of Online Deception: What Makes Automated Text Convincing? In Proceedings of the 31st Annual ACM Symposium on Applied Computing, Pisa, Italy, 6-8 April 2016; pp. 1115-1120.

42. Bates, R.; Khasawneh, S. Self-Efficacy and College Students' Perceptions and Use of Online Learning Systems. Comput. Hum. Behav. 2007, 23, 175-191. [CrossRef]

43. Vishnumolakala, V.R.; Southam, D.C.; Treagust, D.F.; Mocerino, M.; Qureshi, S. Students' Attitudes, Self-Efficacy and Experiences in a Modified Process-Oriented Guided Inquiry Learning Undergraduate Chemistry Classroom. Chem. Educ. Res. Pract. 2017, 18, 340-352. [CrossRef]

44. Bandura, A. Self-Efficacy: The Exercise of Control; W.H. Freeman and Company: New York, NY, USA, 1997.

45. Schwarzer, R.; Warner, L.M. Perceived Self-Efficacy and Its Relationship to Resilience. In Resilience in Children, Adolescents, and Adults: Translating Research into Practice; Prince-Embury, S., Saklofske, D.H., Eds.; Springer Science + Business Media: New York, NY, USA, 2013; pp. 139-150, ISBN 978-1-4614-4938-6.

46. Hocevar, K.P.; Flanagin, A.J.; Metzger, M.J. Social Media Self-Efficacy and Information Evaluation Online. Comput. Hum. Behav. 2014, 39, 254-262. [CrossRef]

47. Kundu, A.; Ghose, A. The Relationship between Attitude and Self Efficacy in Mathematics among Higher Secondary Students. J. Hum. Soc. Sci. 2016, 21, 25-31. [CrossRef]

48. Yau, H.K.; Leung, Y.F. The Relationship between Self-Efficacy and Attitudes towards the Use of Technology in Learning in Hong Kong Higher Education. In Proceedings of the International MultiConference of Engineers and Computer Scientists, Hong Kong, China, 14-16 March 2018; pp. 832-834.

49. Tsai, P.-S.; Tsai, C.-C.; Hwang, G.-H. Elementary School Students' Attitudes and Self-Efficacy of Using PDAs in a Ubiquitous Learning Context. Australas. J. Educ. Technol. 2010, 26, 297-308. [CrossRef]

50. Kardas, M.; O’Brien, E. Easier Seen than Done: Merely Watching Others Perform Can Foster an Illusion of Skill Acquisition. Psychol. Sci. 2018, 29, 521-536. [CrossRef]

51. Stella, M.; Ferrara, E.; De Domenico, M. Bots Increase Exposure to Negative and Inflammatory Content in Online Social Systems. Proc. Natl. Acad. Sci. USA 2018, 115, 12435-12440. [CrossRef]

52. Bolsover, G.; Howard, P. Computational Propaganda and Political Big Data: Moving toward a More Critical Research Agenda. Big Data 2017, 5, 273-276. [CrossRef]

53. Social Media, Sentiment and Public Opinions: Evidence from \#Brexit and \#USElection. Available online: https://ssrn.com/abstract=3182227 (accessed on 20 June 2020).

54. Reuter, C.; Kaufhold, M.; Steinfort, R. Rumors, Fake News and Social Bots in Conflicts and Emergencies: Towards a Model for Believability in Social Media. In Proceedings of the 14th ISCRAM Conference, Albi, France, 21-24 May 2017; ISCRAM: Ocean City, MD, USA, 2017; Comes, T., Bénaben, F., Hanachi, C., Lauras, M., Montarnal, A., Eds.; pp. 583-591.

55. Chao, C.M. Factors Determining the Behavioral Intention to Use Mobile Learning: An Application and Extension of the UTAUT Model. Front. Psychol. 2019, 10, 1-14. [CrossRef]

56. Pedersen, P.E.; Ling, R. Modifying Adoption Research for Mobile Internet Service Adoption: Cross-Disciplinary Interactions. In Proceedings of the 36th Annual Hawaii International Conference on System Sciences, Big Island, HI, USA, 6-9 January 2003. [CrossRef]

57. Wang, H.; Wang, S.-H. User Acceptance of Mobile Internet Based on the Unified Theory of Acceptance and Use of Technology: Investigating the Determinants and Gender Differences. Soc. Behav. Pers. 2010, 38, 415-426. [CrossRef] 
58. Yuan, Y.H.; Tsai, S.B.; Dai, C.Y.; Chen, H.M.; Chen, W.F.; Wu, C.H.; Li, G.; Wang, J. An Empirical Research on Relationships between Subjective Judgement, Technology Acceptance Tendency and Knowledge Transfer. PLOS ONE 2017, 12, 1-22. [CrossRef]

59. Clerwall, C. Enter the Robot Journalist. J. Pract. 2014, 8, 519-531. [CrossRef]

60. Graefe, A.; Haim, M.; Haarmann, B.; Brosius, H.B. Readers' Perception of Computer-Generated News: Credibility, Expertise, and Readability. Journalism 2018, 19, 595-610. [CrossRef]

61. Thurman, N.; Moeller, J.; Helberger, N.; Trilling, D. My Friends, Editors, Algorithms, and I. Digit. J. 2019, 7,447-469. [CrossRef]

62. Glynn, C.J.; Huge, M.E.; Hoffman, L.H. All the News That's Fit to Post: A Profile of News Use on Social Networking Sites. Comput. Hum. Behav. 2012, 28, 113-119. [CrossRef]

63. Warner-Søderholm, G.; Bertsch, A.; Sawe, E.; Lee, D.; Wolfe, T.; Meyer, J.; Engel, J.; Fatilua, U.N. Who Trusts Social Media? Comput. Hum. Behav. 2018, 81, 303-315. [CrossRef]

64. Khan, M.L.; Idris, I.K. Recognise Misinformation and Verify before Sharing: A Reasoned Action and Information Literacy Perspective. Behav. Inf. Technol. 2019, 38, 1194-1212. [CrossRef]

65. Sundar, S.S.; Waddell, T.F.; Jung, E.H. The Hollywood Robot Syndrome: Media Effects on Older Adults' Attitudes toward Robots and Adoption Intentions. In Proceedings of the 11th ACM/IEEE International Conference on Human-Robot Interaction (HRI), Christchurch, New Zealand, 7-10 March 2016; pp. 343-350. [CrossRef]

66. Waddell, T.F. A Robot Wrote This? How Perceived Machine Authorship Affects News Credibility. Digit. J. 2018, 6, 236-255. [CrossRef]

67. Gallup. Indicators of News Media Trust; Knight Foundation: 2018. Available online: https: //kf-site-production.s3.amazonaws.com/media_elements/files/000/000/216/original/KnightFoundation_ Panel4_Trust_Indicators_FINAL.pdf (accessed on 12 June 2020).

(C) 2020 by the authors. Licensee MDPI, Basel, Switzerland. This article is an open access article distributed under the terms and conditions of the Creative Commons Attribution (CC BY) license (http://creativecommons.org/licenses/by/4.0/). 